\title{
Synthesis of New Bicyclic Hydroxamic Acids with Cytotoxic Activity
}

\author{
Iker S. Escalona-Torres, ${ }^{1}$ Francisco Yuste, ${ }^{1}$ and Rubén Sánchez-Obregón ${ }^{1 *}$ \\ ${ }^{1}$ Instituto de Química, Universidad Nacional Autónoma de México. Circuito Exterior s/n. Ciudad Universitaria, Coyoacán 04510, \\ Ciudad de México, México. \\ Corresponding author e-mail: rubens@unam.mx Tel.: +52 55 56224406; fax: +52 5556162217.
}

Received October $15^{\text {th }}, 2017$; Accepted October $23^{\text {th }}, 2017$

\begin{abstract}
Six new bicyclic hydroxamic acids were synthesized through an uncommon nitro group rearrangement between $\beta$-nitrostyrenes and dimedone. The structures of all the new synthesized compounds were confirmed using a combination of FTIR, ${ }^{1} \mathrm{H}$ NMR, ${ }^{13} \mathrm{C}$ NMR and mass spectral data. Likewise, the cytotoxic activity of the obtained products was evaluated in six different cancer cell lines. Two compounds showed significant potency on two cancer cell lines with $\mathrm{IC}_{50}$ between $9.31 \pm 0.1$ and $23.38 \pm 0.9 \mu \mathrm{M}$.
\end{abstract}

Key words: Hydroxamic acids; Michael addition; nitro group rearrangement; cytotoxic activity

\section{Introduction}

Hydroxamic acids whether acyclic or cyclic, are interesting compounds which contain a hydroxyl group on a nitrogen atom of an amide or a lactam group. They are found to be associated with various activities such as anti-HIV [1], anti-Alzheimer diseases [2], in the treatment of metal poisoning [3], malaria [4], allergic diseases [5], and tuberculosis [6]. Also, it has been reported that hydroxamic acids possess cytotoxic activity as result of the inhibition of the histone deacetylase (HDAC) enzyme [7]. Some hydroxamic acids are presented in Fig.1, and these compounds exert significant cytotoxic activity in vitro, especially on prostate cancer cells [8-10].

In the present work, we targeted the synthesis of several bicyclic hydroxamic acid derivatives, employing an uncommon ni-
Resumen. Se sintetizaron seis nuevos ácidos hidroxámicos bicíclicos a través de una transposición poco común del grupo nitro, entre $\beta$-nitroestirenos y dimedona. Las estructuras de todos compuestos sintetizados se determinaron mediante FTIR, ${ }^{1} \mathrm{H}$ NMR, ${ }^{13} \mathrm{C}$ RMN y espectrometría de masas. Asimismo, se evaluó la actividad citotóxica de los productos obtenidos en seis líneas celulares de diferentes tipos de cáncer. Dos compuestos mostraron actividad importante contra dos líneas celulares de cáncer con $\mathrm{IC}_{50}$ entre $9.31 \pm 0.1$ y $23.38 \pm 0.9 \mu \mathrm{M}$.

Palabras clave: Ácidos hidroxámicos; adición de Michael; transposición del grupo nitro; actividad citotóxica.

tro group rearrangement in the reaction between $\beta$-nitrostyrenes [11-14] and dimedone using a similar procedure to that reported by Larson et al [15]. The cytotoxicity of the obtained compounds was evaluated to establish its potential anticancer activity.

\section{Results and Discussion}

\section{Chemistry}

The $\beta$-nitrostyrenes $\mathbf{2}$ used for the synthesis of hydroxamic acids 3, were prepared from a similar procedure [16], from nitromethane (1.1 equiv.), the corresponding benzaldehydes 1a-f (1.0 equiv.) and $\mathrm{AcONH}_{4}$ ( 0.4 equiv.) in glacial acetic acid under reflux for $2 \mathrm{~h}$.<smiles>O=C1C(O)Oc2ccccc2N1O</smiles><smiles>O=C1CCc2cc(Cl)ccc2N1O</smiles>

$\mathrm{HCDHQ}$<smiles>CCCCCC[C@H]1C[C@@H](c2cccc3ccccc23)CC(=O)N1O</smiles>

BMD188<smiles>O=C(/C=C/c1cccc(C(=O)NO)c1)NO</smiles>

CBHA

Fig. 1. Representative hydroxamic acids with HDAC inhibitory activity. 
The intermediate nitrostyrenes (2a-f) were obtained in yields ranging from 91 to $95 \%$ and their structures were determined by m.p., NMR and MS data. The $\beta$-nitrostyrenes 2a-f were reacted with dimedone in the presence of 2.2 equiv. of $\mathrm{MeONa}$ in dry $\mathrm{MeOH}$, under nitrogen at $35-40^{\circ} \mathrm{C}$, yielding the target hydroxamic acids 3a-f (Scheme 1).

The mechanism whereby the hydroxamic acids 3a-f are formed is not clear; a proposal is shown (Scheme2) supported by examples from literature $[17,18]$. The Michael addition of dimedone anion to nitrostyrene would lead to intermediate $\mathbf{A}$, which in the presence of methanol and the methoxide ion would produce the nitrile oxide $\mathbf{B}$, which undergoes a hydroxyl group attack toward the triple bond of the nitrile oxide producing in- termediate $\mathbf{C}$. Finally, the protonation and dehydration reactions of this intermediate gives the compound $\mathbf{D}$ which shows a tautomeric equilibrium with the hydroxamic acid $\mathbf{3 a}$.

The chemical identification of products $\mathbf{3 a - f}$ was carried out using FTIR, ${ }^{1} \mathrm{H}$ NMR, ${ }^{13} \mathrm{C}$ NMR and mass spectral data. Finally, the hydrogenation reaction for compound $\mathbf{3 a}$ in the presence of Raney Nickel in ethanol produced compound $\mathbf{4}$, and subsequent dehydrogenation with $\mathrm{Pd} / \mathrm{C}$ led to the pyrrole 5 (Scheme 3), confirming the structure of 1-hydroxy-6,6-dimethyl-3-phenyl-3,5,6,7tetrahydro- $1 H$-indole-2,4-dione (3a) and probably the heterocyclic framework of the other products, instead of 2-hydroxyiminofuran derivatives [19].Additionally, to corroborate the structure of pyrrole 5, it was prepared through a different synthetic route [20].

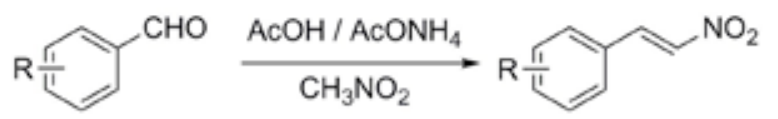

1a: $\mathrm{R}=\mathrm{H}$

1b: $\mathrm{R}=\mathrm{o}-\mathrm{CH}_{3}$

1c: $\mathrm{R}=0-\mathrm{OCH}_{3}$

1d: $\mathrm{R}=0-\mathrm{Cl}$

1e: $\mathrm{R}=p-\mathrm{CH}_{3}$

1f: $\mathrm{R}=p \cdot \mathrm{Br}$

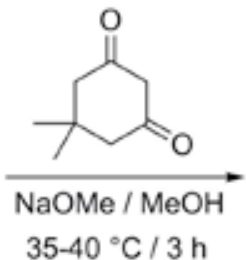

2a-f

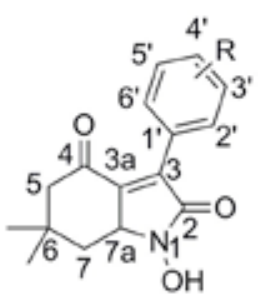

3a-f

Scheme 1. Synthesis of hydroxamic acids 3a-f.

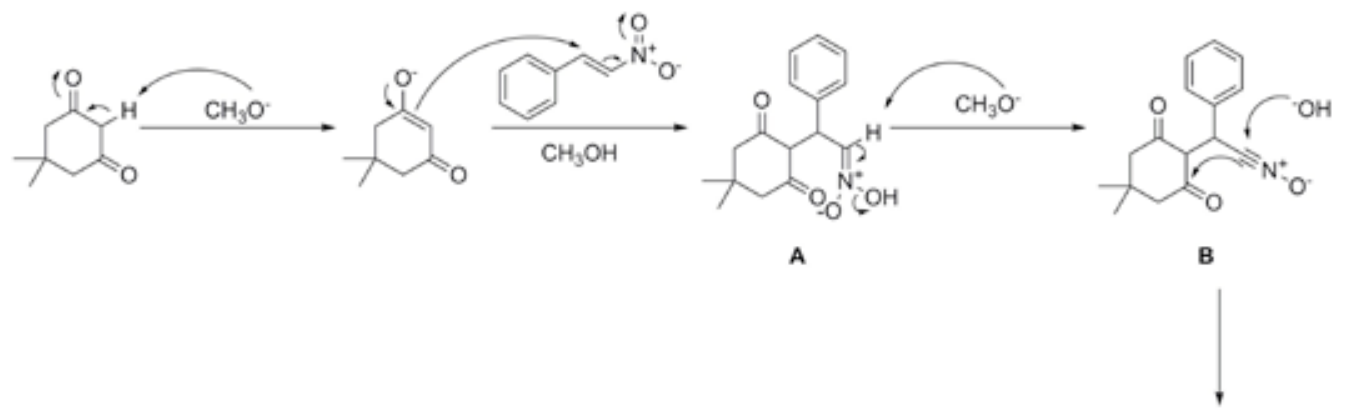

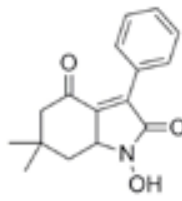

3a

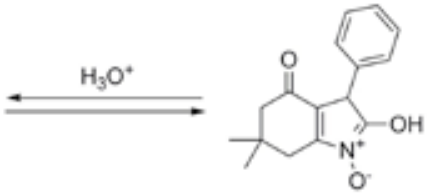

D

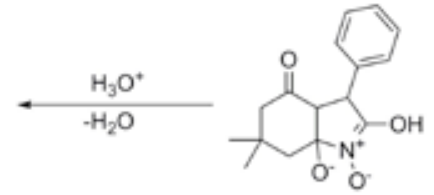

C

Scheme 2. Proposed mechanism for the formation of hydroxamic acids 3a.

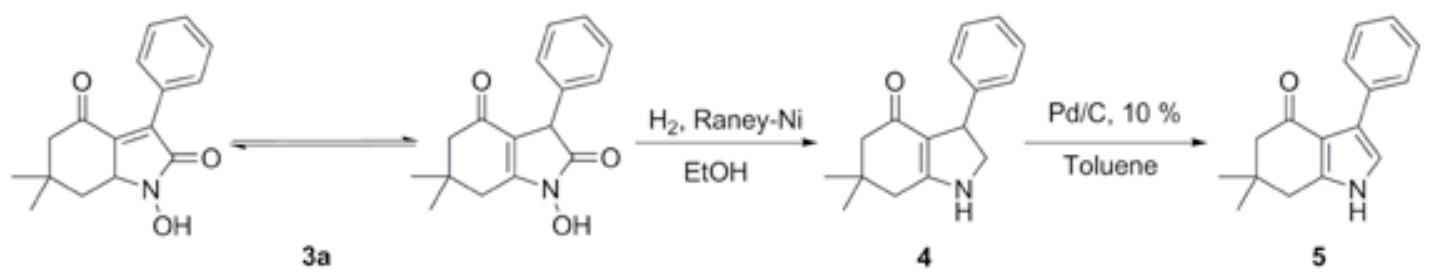

Scheme 3. Synthesis of pyrrole derivative (5) to confirm the structure of $\mathbf{3 a}$. 


\section{Cytotoxic activity}

Cytotoxicity in vitro for compounds 3a-f was evaluated in six cancer cell lines, such as K562 (leukemia), HCT-15 (colon), MCF-7 (breast), PC-3 (prostate), U251 (CNS) and SKLU-1 (lung), using the Sulforhodamine B assay as is described by the National Cancer Institute of the United States of America [21]. Preliminary screening with $50 \mu \mathrm{M}$ solution of each compound allowed to determine that compounds 3a-f were more active in PC-3 and SKLU-1 cell lines. Then the concentration for tested compounds resulted $50 \%$ inhibition of cell proliferation $\left(\mathrm{IC}_{50}\right)$ was calculated. The results are summarized in the Table 1 . In accordance with the $\mathrm{IC}_{50}$ values the compounds showed moderate cytotoxic activity against PC-3 and SKLU-1, among them $3 \mathbf{e}\left(\mathrm{IC}_{50}=23.38 \pm 0.9 \mu \mathrm{M}\right.$ against $\mathrm{PC}-3$ and $9.31 \pm 0.1 \mu \mathrm{M}$ against SKLU-1) compared to suberoylanilide hydroxamic acid (SAHA), a drug used in cancer chemotherapy, $\mathrm{IC}_{50}=0.91 \pm 0.04$ $\mu \mathrm{M}$ and $0.91 \pm 0.09 \mu \mathrm{M}$, respectively, another compound which showed good cytotoxic activity was $\mathbf{3 f}$ with $\mathrm{IC}_{50}$ values of $22.89 \pm 1.8 \mu \mathrm{M}$ and $15.3 \pm 1.1 \mu \mathrm{M}$, for the respective cell lines (Tables 2-4, Figures 2-12). This suggests that the presence of substituent on $4^{\prime}$ of the aromatic ring plays an important role in the cytotoxicity in comparison with the substituent located at $2^{\prime}$ as in $\mathbf{3 b}$-d or when R is hydrogen (3a).

Table 1. Bicyclic hydroxamic acids and their cytotoxic activity in vitro against two cancer cell lines.

\begin{tabular}{cccccc}
\hline Entry & $\mathrm{R}$ & Compound & Yield $/ \%$ & \multicolumn{2}{c}{$\mathrm{IC}_{50} / \mu \mathrm{M}$} \\
& & & & PC-3 & SKLU-1 \\
\hline 1 & $\mathrm{H}$ & $\mathbf{3 a}$ & 80 & $45.26 \pm 1.8$ & $20.41 \pm 0.9$ \\
2 & $o-\mathrm{CH}_{3}$ & $\mathbf{3 b}$ & 72 & $>100$ & $87.11 \pm 7.2$ \\
3 & $o-\mathrm{OCH}_{3}$ & $\mathbf{3 c}$ & 75 & $\mathrm{a}$ & $\mathrm{a}$ \\
4 & $o-\mathrm{Cl}$ & $\mathbf{3 d}$ & 83 & $63.42 \pm 2.0$ & $20.86 \pm 0.2$ \\
5 & $p-\mathrm{CH}_{3}$ & $\mathbf{3 e}$ & 57 & $23.38 \pm 0.9$ & $9.31 \pm 0.1$ \\
6 & $p-\mathrm{Br}$ & $\mathbf{3 f}$ & 64 & $22.89 \pm 1.8$ & $15.3 \pm 1.1$ \\
7 & & SAHA & & $0.91 \pm 0.0 .04$ & $0.091 \pm 0.09$ \\
\hline
\end{tabular}

${ }^{\mathrm{a}}$ No activity

Table 2. Cytotoxic activity of SAHA.

\begin{tabular}{cccccc}
\hline Cancer cell line & Concentration $(\mu \mathrm{M})$ & \multicolumn{5}{l}{ Inhibition of the proliferation $(\%)$} \\
\hline PC-3 & 1.00 & 87.76 & 86.85 & 95.40 & 91.80 \\
& 3.10 & 73.98 & 75.37 & 74.80 & 72.20 \\
& 1.00 & 60.57 & 45.20 & 54.00 & 49.70 \\
SKLU-1 & 0.31 & 29.51 & 35.37 & 23.30 & 32.70 \\
& 1.00 & 91.72 & 91.15 & 90.37 & 90.94 \\
& 3.10 & 83.78 & 80.61 & 78.52 & 82.30 \\
& 1.00 & 59.36 & 59.28 & 52.84 & 56.01 \\
\hline
\end{tabular}

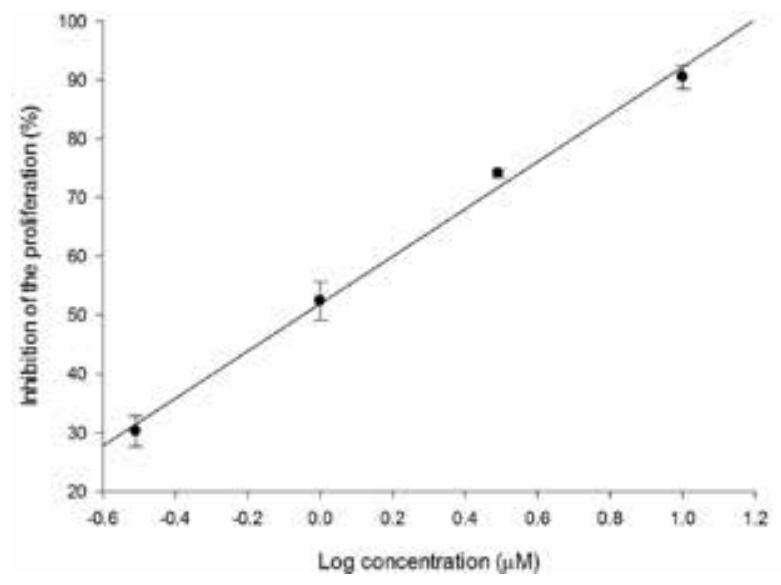

Fig. 2. Relation between PC-3 inhibition percentage and log of concentration for SAHA $\left(\mathrm{R}^{2}=0.995\right)$.

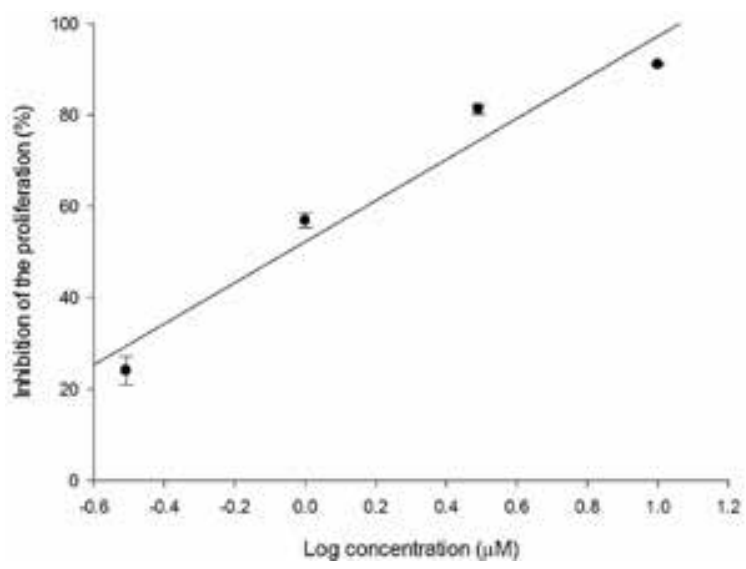

Fig. 3. Relation between SKLU-1 inhibition percentage and log of concentration for SAHA $\left(\mathrm{R}^{2}=0.949\right)$. 
Table 3. Cytotoxic activity of compounds 3a-f in PC-3.

\begin{tabular}{|c|c|c|c|c|c|c|}
\hline \multirow{2}{*}{$\frac{\text { Compound }}{\mathbf{3 a}}$} & \multirow{2}{*}{$\begin{array}{c}\text { Concentration }(\mu \mathrm{M}) \\
80.00\end{array}$} & \multicolumn{5}{|c|}{ Inhibition of the proliferation (\%) } \\
\hline & & 93.50 & 100.00 & 100.00 & 100.00 & $*$ \\
\hline & 60.00 & 81.80 & 96.70 & 53.90 & 53.87 & $*$ \\
\hline & 40.00 & 23.30 & 41.70 & 30.06 & 34.57 & $*$ \\
\hline & 20.00 & 0.00 & 0.00 & 0.52 & 18.71 & $*$ \\
\hline \multirow[t]{4}{*}{ 3d } & 100.00 & 100.00 & 100.00 & $*$ & $*$ & $*$ \\
\hline & 80.00 & 63.60 & 76.30 & * & $*$ & $*$ \\
\hline & 60.00 & 26.60 & 3.57 & $*$ & $*$ & $*$ \\
\hline & 40.00 & 13.20 & 15.70 & $*$ & * & $*$ \\
\hline \multirow[t]{3}{*}{$3 \mathbf{e}$} & 50.00 & 100.00 & 100.00 & 100.00 & 100.00 & $*$ \\
\hline & 25.00 & 44.60 & 47.90 & 78.28 & 77.11 & * \\
\hline & 12.50 & 0.00 & 9.58 & 0.00 & 4.52 & $*$ \\
\hline \multirow[t]{3}{*}{$3 \mathbf{f}$} & 50.00 & 100.00 & 100.00 & 100.00 & 100.00 & 100.00 \\
\hline & 25.00 & 66.01 & 63.23 & 41.80 & 22.00 & 69.77 \\
\hline & 12.50 & 17.30 & 20.46 & 4.08 & 0.00 & 10.87 \\
\hline
\end{tabular}

*Unregistered data

Table 4. Cytotoxic activity of compounds $\mathbf{3 a - f}$ in SKLU-1.

\begin{tabular}{|c|c|c|c|c|}
\hline \multirow{2}{*}{$\frac{\text { Compound }}{\text { 3a }}$} & \multirow{2}{*}{$\frac{\text { Concentration }(\mu \mathrm{M})}{50.00}$} & \multicolumn{3}{|c|}{ Inhibition of the proliferation (\%) } \\
\hline & & 100.00 & 100.00 & 92.92 \\
\hline & 25.00 & 68.86 & 51.32 & 42.99 \\
\hline & 12.50 & 10.07 & 22.69 & 26.95 \\
\hline & 6.25 & 0.00 & 12.23 & 12.13 \\
\hline \multirow[t]{4}{*}{$\mathbf{3 b}$} & 100.00 & 82.09 & 82.51 & 94.04 \\
\hline & 75.00 & 39.10 & 20.28 & 67.15 \\
\hline & 50.00 & 20.75 & 11.12 & 59.35 \\
\hline & 25.00 & 2.47 & 0.00 & 16.88 \\
\hline \multirow[t]{4}{*}{ 3d } & 50.00 & 96.38 & 77.54 & 80.87 \\
\hline & 25.00 & 57.43 & 55.52 & 55.50 \\
\hline & 12.50 & 19.67 & 28.92 & 24.38 \\
\hline & 6.25 & 0.00 & 18.90 & 16.53 \\
\hline \multirow[t]{4}{*}{$3 e$} & 25.00 & 98.59 & 95.07 & 95.90 \\
\hline & 12.50 & 46.88 & 48.36 & 50.43 \\
\hline & 6.25 & 32.42 & 27.73 & 27.34 \\
\hline & 3.12 & 20.74 & 19.19 & 18.30 \\
\hline \multirow[t]{4}{*}{$3 f$} & 50.00 & 100.00 & 100.00 & 100.00 \\
\hline & 25.00 & 83.64 & 92.12 & 54.24 \\
\hline & 12.50 & 31.60 & 41.64 & 35.56 \\
\hline & 6.25 & 13.20 & 15.74 & 2.02 \\
\hline
\end{tabular}




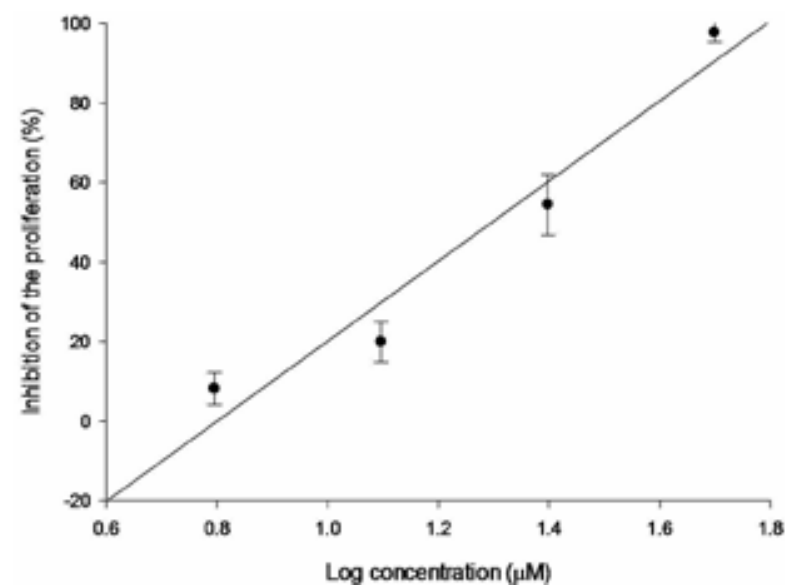

Fig. 4. Relation between SKLU-1 inhibition percentage and log of concentration for compound $3 \mathbf{a}\left(\mathrm{R}^{2}=0.946\right)$.

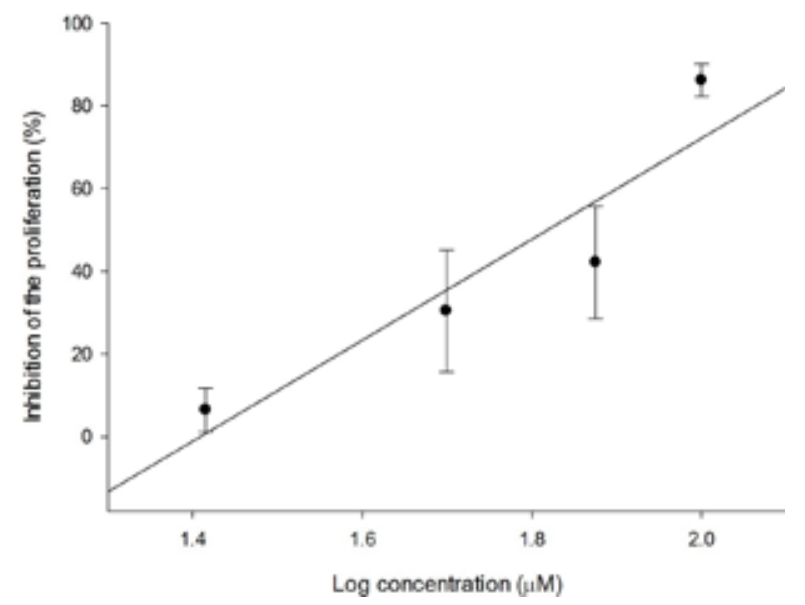

Fig. 6. Relation between SKLU-1 inhibition percentage and log of concentration for $\mathbf{3 b}$ compound $\left(\mathrm{R}^{2}=0.859\right)$.

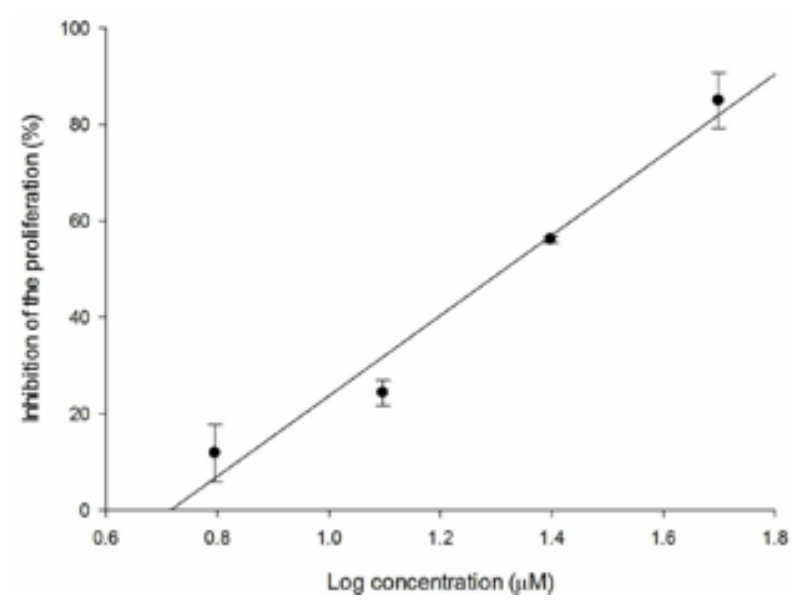

Fig. 8. Relation between SKLU-1 inhibition percentage and log of concentration for $\mathbf{3 d}$ compound $\left(\mathrm{R}^{2}=0.972\right)$.

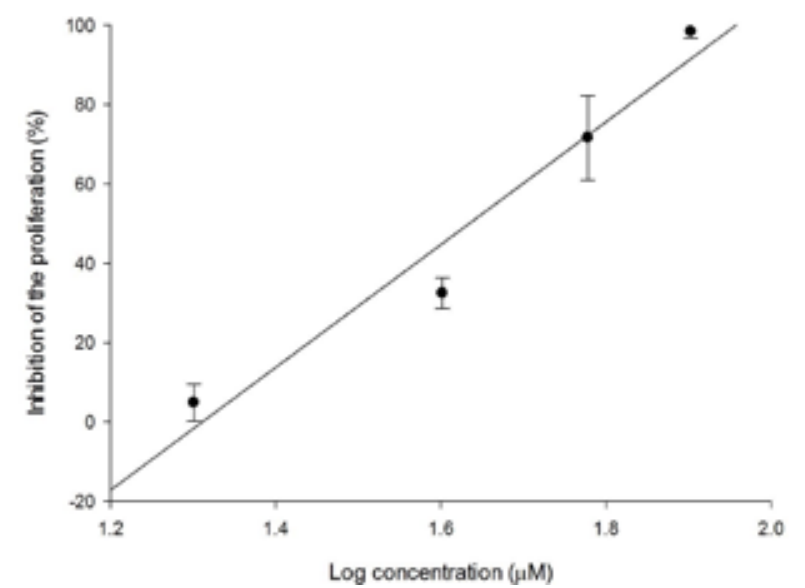

Fig. 5. Relation between PC-3 inhibition percentage and log of concentration for $3 \mathbf{a}$ compound $\left(\mathrm{R}^{2}=0.952\right)$.

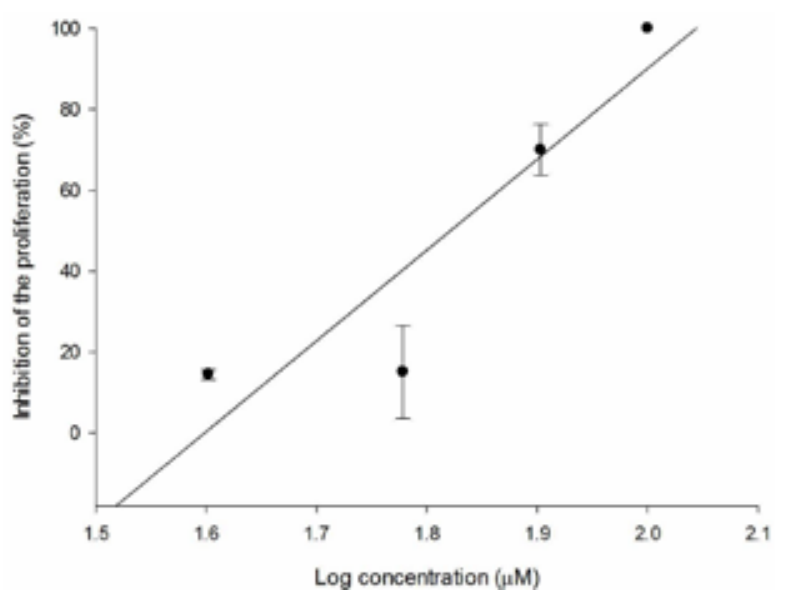

Fig. 7. Relation between PC-3 inhibition percentage and log of concentration for $\mathbf{3 d}$ compound $\left(\mathrm{R}^{2}=0.828\right)$.

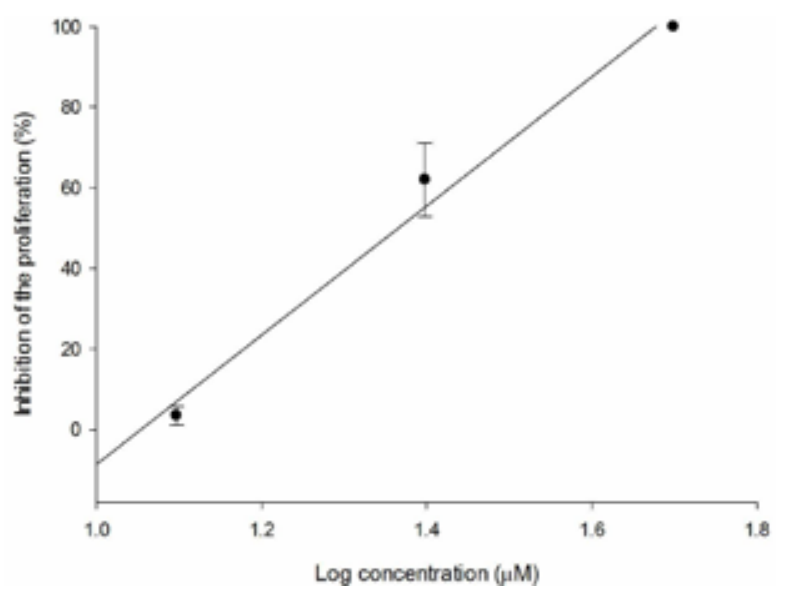

Fig. 9. Relation between PC-3 inhibition percentage and log of concentration for $3 \mathbf{e}$ compound $\left(\mathrm{R}^{2}=0.985\right)$. 


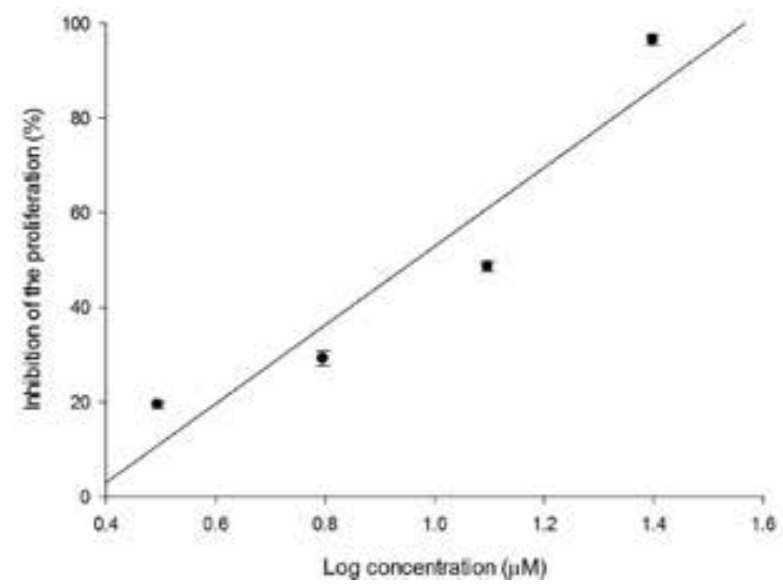

Fig. 10. Relation between SKLU-1 inhibition percentage and log of concentration for $3 \mathbf{e}$ compound $\left(\mathrm{R}^{2}=0.891\right)$.

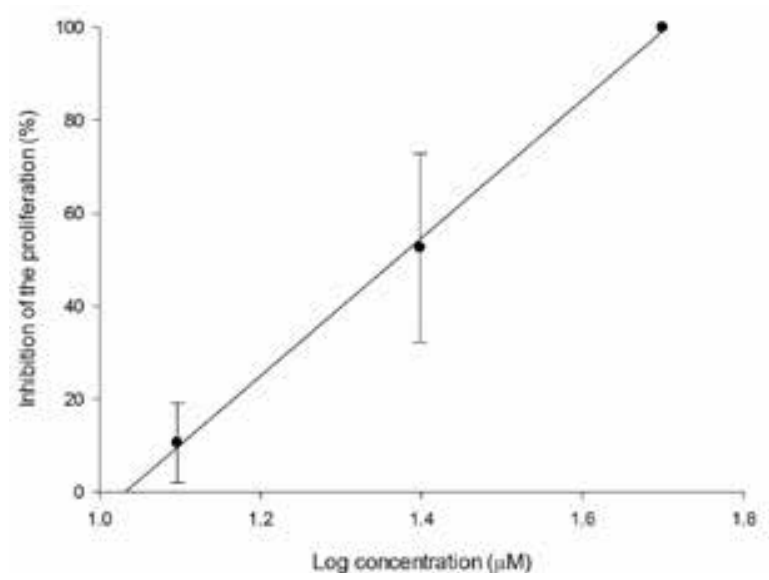

Fig. 11. Relation between PC-3 inhibition percentage and log of concentration for $\mathbf{3 f}$ compound $\left(\mathrm{R}^{2}=0.998\right)$.

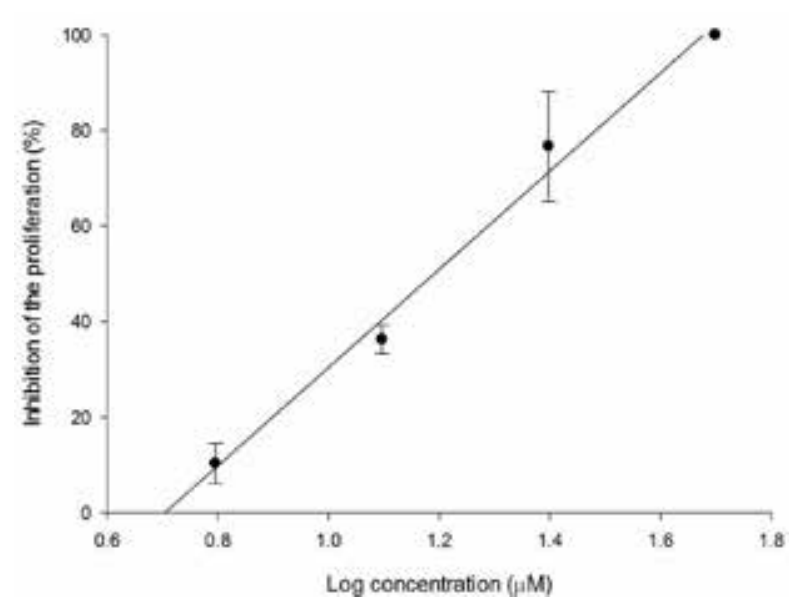

Fig. 12. Relation between SKLU-1 inhibition percentage and log of concentration for $\mathbf{3 f}$ compound $\left(\mathrm{R}^{2}=0.989\right)$

\section{Conclusion}

Six new bicyclic hydroxamic acids were synthesized in a twostep sequence starting from aromatic aldehydes 1 . The $\beta$-nitrostyrenes $\mathbf{2}$ were obtained by Henry reaction of $\mathbf{1}$ with nitromethane followed by their reaction with dimedone in basic medium, through an uncommon reaction of nitro group, to obtain the products 3 in good yields (57-80\%). The cytotoxicity of these compounds has been evaluated against different cancer cell lines. Thus, compounds $\mathbf{3 e}$ and $\mathbf{3 f}$ showed good cytotoxic activity.

\section{Experimental}

\section{Materials}

Starting materials and solvents were purchased from Sigma-Aldrich Co. and used without further purification. Melting points were determined using an Electrothermal Digital Melting Point Apparatus. IR spectra were measured using a Bruker Tensor 27 FT-IR spectrometer. ${ }^{1} \mathrm{H}$ NMR $(300 \mathrm{MHz})$ and ${ }^{13} \mathrm{C}$ NMR $(75 \mathrm{MHz})$ spectra were recorded in a Jeol Eclipse 300 $\mathrm{MHz}$ spectrometer using $\mathrm{CDCl}_{3}$ as solvent and TMS as internal reference. Data for ${ }^{1} \mathrm{H}$ NMR are recorded as follows: chemical shift ( $\delta / \mathrm{ppm})$; multiplicity: s: singlet, d: doublet, dd: double doublet, $\mathrm{t}$ : triplet, td: triple doublet, $\mathrm{m}$ : multiplet or unresolved, bs: broad signal; the coupling constants are expressed in $\mathrm{Hz}$. Data for ${ }^{13} \mathrm{C}$ NMR are reported in terms of chemical shifts $(\delta / \mathrm{ppm})$. HR-EI-MS and HR-ESI-MS spectra were obtained in a Jeol M Station JMS-700 and a Jeol AccuTOF JMS-T-100 LC. Flash chromatography was performed with silica gel 60 (230-400 mesh ASTM). Silica gel $60 \mathrm{~F}_{254}$ aluminum plates were used for TLC analysis. Developing agents: phosphomolybdic acid $10 \%$ in ethanol. The nitrostyrenes were synthesized following the reported procedure [16]. All products were purified by recrystallization.

\section{General procedure for the synthesis of compounds $2 \mathrm{a}-\mathrm{f}$.}

Each benzaldehyde $(4 \mathrm{mmol})$ was treated with nitromethane $(4.4 \mathrm{mmol})$, ammonium acetate $(1.6 \mathrm{mmol})$ in glacial acetic acid $(5 \mathrm{~mL})$. The mixture was stirred and refluxed for $2 \mathrm{~h}$ and the reaction mixture was cooled to $0{ }^{\circ} \mathrm{C}$. The obtained products were filtered off and recrystallized from ethanol to give 2a-f. The ${ }^{1} \mathrm{H}$ and ${ }^{13} \mathrm{C}$ NMR spectra were in accordance to those cited in the literature for each described compound [12-14].

[(E)-1-(2-nitroethenyl)]benzene (2a).Isolated yield $92 \%$; yellowish solid; m.p.: $55-56{ }^{\circ} \mathrm{C}$ (from ethanol) (Ref. [12] 55-57 ${ }^{\circ} \mathrm{C}$, Ref. [13] 59-62 $\left.{ }^{\circ} \mathrm{C}\right) .{ }^{1} \mathrm{H}$ NMR $\left(300 \mathrm{MHz}, \mathrm{CDCl}_{3}\right): \delta=7.43-7.32$ (m, 2H, CHarom), 7.52-7.48 (m, 1H, CHarom), 7.57-7.53 (m, 2H, 2CHarom), 7.59 (d, $J=14 \mathrm{~Hz}, 1 \mathrm{H}, \mathrm{CH}$ olefinic), 8.02 (d, $1 \mathrm{H}, J=14 \mathrm{~Hz}, \mathrm{CH}$ olefinic) ppm; ${ }^{13} \mathrm{C}$ NMR $\left(75 \mathrm{MHz}, \mathrm{CDCl}_{3}\right)$ : $\delta=124.3,129.6,130.7,131.5,136.2,139.5 \mathrm{ppm}$. 
1-Methyl-2-[(E)-2-nitroethenyl]benzene (2b). Isolated yield 95 $\%$; yellow solid; m.p.: $63-65^{\circ} \mathrm{C}$ (from ethanol) (Ref. [13] 112-118 ${ }^{\circ} \mathrm{C}$, Ref. [14] yellow oil). ${ }^{1} \mathrm{H}$ NMR (300 MHz, $\mathrm{CDCl}_{3}$ ): $\delta=2.47$ (s, 3H, $\left.\mathrm{CH}_{3}\right), 7.27-7.24\left(\mathrm{~m}, 2 \mathrm{H}, \mathrm{CH}_{2}\right.$ arom), 7.39-7.35 (m, $1 \mathrm{H}$, $\mathrm{CH}$ arom), 7.50-7.47 (m, 2H, CH olefinic, $\mathrm{CH}$ arom), 8.28 (d, $J$ $=13.6 \mathrm{~Hz}, 1 \mathrm{H}, \mathrm{CH}$ olefinic) ppm; ${ }^{13} \mathrm{C}$ NMR $\left(75 \mathrm{MHz}, \mathrm{CDCl}_{3}\right): \delta$ $=20.1,126.9,127.5,129.1,131.6,132.1,136.9,137.8,139.4 \mathrm{ppm}$.

1-Methoxy-2-[(E)-2-nitroethenyl]benzene (2c). Isolated yield $94 \%$; yellow solid; m.p.: $60-62{ }^{\circ} \mathrm{C}$ (from ethanol) (Ref. [14] 50$\left.52{ }^{\circ} \mathrm{C}\right) .{ }^{1} \mathrm{H}$ NMR $\left(300 \mathrm{MHz}, \mathrm{CDCl}_{3}\right): \delta=3.98\left(\mathrm{~s}, 3 \mathrm{H}, \mathrm{OCH}_{3}\right)$, 7.06-6.99 (m, 2H, 2CH arom), 7.50-7.46 (m, 2H, 2CH arom), 7.91 (d, $J=13.6 \mathrm{~Hz}, 1 \mathrm{H}, \mathrm{CH}$ olefinic), 8.16 (d, $J=13.6 \mathrm{~Hz}, 1 \mathrm{H}$, $\mathrm{C} H$ olefinic) ppm; ${ }^{13} \mathrm{C} \mathrm{NMR}\left(75 \mathrm{MHz}, \mathrm{CDCl}_{3}\right): \delta=55.8,111.6$, $119.4,121.3,132.6,133.6,135.6,138.5,159.7 \mathrm{ppm}$.

1-Chloro-2-[(E)-2-nitroethenyl]benzene (2d). Isolated yield $91 \%$; brown solid; m.p.: $42-44{ }^{\circ} \mathrm{C}$ (from ethanol) (Ref. [12] 40-42, Ref. [14] 48-52 $\left.{ }^{\circ} \mathrm{C}\right) .{ }^{1} \mathrm{H}$ NMR $\left(300 \mathrm{MHz}, \mathrm{CDCl}_{3}\right): \delta=$ 7.36-7.32 (m, 1H, CH arom), $7.43(\mathrm{td}, J=7.7, J=1.5 \mathrm{~Hz}$, $1 \mathrm{H}, \mathrm{CH}$ arom), $7.50(\mathrm{dd}, J=8.0, J=1.1 \mathrm{~Hz}, 1 \mathrm{H}, \mathrm{CH}$ arom), 7.61-7.57 (m, 2H, CH olefinic, $\mathrm{CH}$ arom), 8.41 (d, 1H, $J=13.7$ $\mathrm{Hz}, \mathrm{CH}$ olefinic) ppm; ${ }^{13} \mathrm{C}$ NMR $\left(75 \mathrm{MHz}, \mathrm{CDCl}_{3}\right): \delta=127.7$, 128.7, 128.8, 130.9, 133.1, 135.3, 136.2, $139.1 \mathrm{ppm}$.

1-Methyl-4-[(E)-2-nitroethenyl]benzene (2e). Isolated yield $93 \%$; yellow solid; m.p.: $88-90{ }^{\circ} \mathrm{C}$ (from ethanol) (Ref. [12] 100-102 ${ }^{\circ} \mathrm{C}$, Ref. [13] 102-106 ${ }^{\circ} \mathrm{C}$, Ref. [14] 106-108 $\left.{ }^{\circ} \mathrm{C}\right) .{ }^{1} \mathrm{H}$ $\operatorname{NMR}\left(300 \mathrm{MHz}, \mathrm{CDCl}_{3}\right): \delta=2.44\left(\mathrm{~s}, 3 \mathrm{H}, \mathrm{CH}_{3}\right), 7.28(\mathrm{~d}, J=$ $8.1 \mathrm{~Hz}, 2 \mathrm{H}, 2 \mathrm{CH}$ arom), $7.47(\mathrm{~d}, J=8.1 \mathrm{~Hz}, 2 \mathrm{H}, 2 \mathrm{CH}$ arom), 7.59 (d, $J=13.7 \mathrm{~Hz}, 1 \mathrm{H}, \mathrm{CH}$ olefinic), 8.01 (d, $J=13.7 \mathrm{~Hz}, 1 \mathrm{H}$, $\mathrm{C} H$ olefinic) ppm; ${ }^{13} \mathrm{C} \mathrm{NMR}\left(75 \mathrm{MHz}, \mathrm{CDCl}_{3}\right): \delta=21.9,127.4$, $129.4,130.3,136.5,139.4,143.3 \mathrm{ppm}$.

1-Bromo-4-[(E)-2-nitroethenyl]benzene (2f). Isolated yield 95 $\%$; light yellow solid; m.p.: $115-118{ }^{\circ} \mathrm{C}$ (from ethanol) (Ref. [12] $148-150{ }^{\circ} \mathrm{C}$, Ref. [14] $\left.153-155^{\circ} \mathrm{C}\right) .{ }^{1} \mathrm{H}$ NMR $(300 \mathrm{MHz}$, $\left.\mathrm{CDCl}_{3}\right): \delta=7.40$ (d, $2 \mathrm{H}, J=8.4 \mathrm{~Hz}, 2 \mathrm{CH}$ arom), 7.60-7.55 (m, 3H, CH olefinic, 2CH arom), 7.93 (d, $J=13.7 \mathrm{~Hz}, 1 \mathrm{H}, \mathrm{CH}$ olefinic) ppm; ${ }^{13} \mathrm{C}$ NMR (75 MHz, $\mathrm{CDCl}_{3}$ ): $\delta=127.0,129.1$, 130.6, 132.9, 137.6, $138.0 \mathrm{ppm}$.

\section{General procedure for the synthesis of compounds 3a-f.}

A solution of sodium methoxide $(10.8 \mathrm{mmol})$ in anhydrous methanol $(15 \mathrm{~mL})$ was heated to $40{ }^{\circ} \mathrm{C}$ and 5,5 -dimethylcyclohexane-1,3-dione $(5.01 \mathrm{mmol})$ was added. To this solution were added the $o-, p$-substituted nitrostyrenes (2a-f) $(5.01 \mathrm{mmol})$ and the mixture was stirred at $35-40{ }^{\circ} \mathrm{C}$ for $3 \mathrm{~h}$, under nitrogen. Then, the mixture was cooled to $0{ }^{\circ} \mathrm{C}$ and acidified with $10 \%$ hydrochloric solution until $\mathrm{pH} 3$. The solid product was filtered off and recrystallized from hexane-acetone.
1-Hydroxy-6,6-dimethyl-3-phenyl-5,6,7,7a-tetrahydro-1Hindole-2,4-dione (3a). Isolated yield $80 \%$; beige crystals; m.p.: $145-148{ }^{\circ} \mathrm{C}$ (from hexane-acetone). ${ }^{1} \mathrm{H}$ NMR $(300 \mathrm{MHz}$, $\left.\mathrm{CDCl}_{3}\right): \delta=1.14\left(\mathrm{~s}, 3 \mathrm{H}, \mathrm{CH}_{3}\right), 1.17\left(\mathrm{~s}, 3 \mathrm{H}, \mathrm{CH}_{3}\right), 2.26(\mathrm{~d}, J=$ $16.6 \mathrm{~Hz}, 1 \mathrm{H}, H-5 \alpha), 2.31$ (d, $J=16.6 \mathrm{~Hz}, 1 \mathrm{H}, H-5 \beta), 2.55$ (dd, $J=2.8 \mathrm{~Hz}, J=18.4 \mathrm{~Hz}, 1 \mathrm{H}, H-7 \alpha), 2.63(\mathrm{dd}, J=1.4 \mathrm{~Hz}, J=$ $18.4 \mathrm{~Hz}, 1 \mathrm{H}, H-7 \beta), 4.89(\mathrm{dd}, J=2.1 \mathrm{~Hz}, J=2.8 \mathrm{~Hz}, 1 \mathrm{H}, H-7 \mathrm{a})$, 7.17-7.31 (m, 5H, $5 \mathrm{H}$ arom) ppm; ${ }^{13} \mathrm{C}$ NMR $\left(75 \mathrm{MHz}, \mathrm{CDCl}_{3}\right)$ : $\delta=28.7,28.8,34.4,36.9,46.0,51.3,116.9,127.6,127.8,128.9$, 137.4, 158.6, 171.8, 193.2 ppm; IR: $\bar{v}=3251(\mathrm{OH}), 1699$ $(\mathrm{C}=\mathrm{O}), 1628(\mathrm{C}=\mathrm{O}) \mathrm{cm}^{-1}$; UV-Vis (methanol, $c=5.16 \cdot 10^{-5} \mathrm{~mol}$ $\left.\mathrm{dm}^{-3}\right): \lambda_{\max }(\varepsilon)=207.0(11793.72), 270.0(10806.07) \mathrm{nm}\left(\mathrm{mol}^{-1}\right.$ $\left.\mathrm{dm}^{3} \mathrm{~cm}^{-1}\right)$; MS (EI, $\left.70 \mathrm{eV}\right): m / z=271[\mathrm{M}]^{+}, 254,187,128,115$; HRMS (EI): $m / z$ calculated for $\mathrm{C}_{16} \mathrm{H}_{17} \mathrm{NO}_{3}[\mathrm{M}]^{+}$271.120843, found 271.1208 .

1-Hydroxy-6,6-dimethyl-3-(2-methylphenyl)-5,6,7,7a-tetrahydro-1H-indole-2,4-dione (3b). Isolated yield $72 \%$; beige crystals; m.p.: 194-196 ${ }^{\circ} \mathrm{C}$ (from hexane-acetone). ${ }^{1} \mathrm{H}$ NMR $\left(300 \mathrm{MHz}, \mathrm{CDCl}_{3}\right): \delta=1.15\left(\mathrm{~s}, 3 \mathrm{H}, \mathrm{CH}_{3}\right), 1.18\left(\mathrm{~s}, 3 \mathrm{H}, \mathrm{CH}_{3}\right)$, $2.25(\mathrm{~d}, J=16.2 \mathrm{~Hz}, 1 \mathrm{H}, H-5 \alpha), 2.29(\mathrm{~d}, J=16.2 \mathrm{~Hz}, 1 \mathrm{H}$, $H-5 \beta$ ), 2.45 (s, 3H, $\mathrm{CH}_{3}$ arom), 2.57 (dd, $J=2.8 \mathrm{~Hz}, J=18.3$ $\mathrm{Hz}, 1 \mathrm{H}, H-7 \alpha$ ), 2.65 (dd, $J=1.7 \mathrm{~Hz}, J=18.3 \mathrm{~Hz}, 1 \mathrm{H}, H-5 \beta$ ), $5.07(\mathrm{dd}, J=2.1 \mathrm{~Hz}, J=2.8 \mathrm{~Hz}, 1 \mathrm{H}, H-7 \mathrm{a}), 6.9(\mathrm{~d}, J=7 \mathrm{~Hz}$, $1 \mathrm{H}, \mathrm{CH}$ arom), 7.08-7.15 (m, 3H, 3CH arom) ppm; ${ }^{13} \mathrm{C}$ NMR $\left(75 \mathrm{MHz}, \mathrm{CDCl}_{3}\right): \delta=19.8,28.7,28.8,34.4,36.9,42.8,51.3$, 117.4, 126.5, 127.5, 131.1, 136.2, 158.9, 171.6, 192.9 ppm; IR: $\bar{v}=3334(\mathrm{OH}), 1704(\mathrm{C}=\mathrm{O}), 1634(\mathrm{C}=\mathrm{O}) \mathrm{cm}^{-1}$; UV-Vis (methanol, $\left.c=4.35 \cdot 10^{-5} \mathrm{~mol} \mathrm{dm}^{-3}\right): \lambda_{\max }(\varepsilon)=209.0(16027.07), 270.5$ (13451.70) nm $\left(\mathrm{mol}^{-1} \mathrm{dm}^{3} \mathrm{~cm}^{-1}\right)$; MS (EI, $\left.70 \mathrm{eV}\right): \mathrm{m} / z=285$ $[\mathrm{M}]^{+}, 268,184,183,141,115$; HRMS (EI): $m / z$ calculated for $\mathrm{C}_{17} \mathrm{H}_{19} \mathrm{NO}_{3}[\mathrm{M}]^{+} 285.1365$, found 285.1377 .

1-Hydroxy-3-(2-methoxyphenyl)-6,6-dimethyl-5,6,7,7a-tetrahydro-1H-indole-2,4-dione (3c). Isolated yield $75 \%$; yellowish white crystals; m.p.; $192-193{ }^{\circ} \mathrm{C}$ (from hexane-acetone). ${ }^{1} \mathrm{H}$ NMR $\left(300 \mathrm{MHz}, \mathrm{CDCl}_{3}\right): \delta=1.14\left(\mathrm{~s}, 3 \mathrm{H}, \mathrm{CH}_{3}\right), 1.15(\mathrm{~s}, 3 \mathrm{H}$, $\mathrm{CH}_{3}$ ), 2.22 (d, $\left.J=16.3 \mathrm{~Hz}, 1 \mathrm{H}, H-5 \alpha\right), 2.26$ (d, $J=16.3 \mathrm{~Hz}, 1 \mathrm{H}$, $H-5 \beta), 2.54$ (dd, $J=2.8 \mathrm{~Hz}, J=18.4 \mathrm{~Hz}, 1 \mathrm{H}, H-7 \alpha$ ), 2.59 (dd, $J$ $=2.1 \mathrm{~Hz}, J=18.4 \mathrm{~Hz}, 1 \mathrm{H}, H-7 \beta), 3.76\left(\mathrm{~s}, 3 \mathrm{H}, \mathrm{OCH}_{3}\right), 5.04(\mathrm{dd}, J$ $=1.7 \mathrm{~Hz}, J=2.8 \mathrm{~Hz}, 1 \mathrm{H}, H-7 \mathrm{a}), 6.8-6.9(\mathrm{~m}, 2 \mathrm{H}, 2 \mathrm{CH}$ arom), 7.1 (d, $J=6.0 \mathrm{~Hz}, 1 \mathrm{H}, \mathrm{CHarom}), 7.2$ (t, $J=7.0 \mathrm{~Hz}, 1 \mathrm{H}, \mathrm{CH}$ arom) ppm; ${ }^{13} \mathrm{C}$ NMR $\left(75 \mathrm{MHz}, \mathrm{CDCl}_{3}\right.$ ): $\delta=28.3,29.1,34.4,37.2$, 42.2, 51.3, 55.8, 111.5, 116.1, 120.9, 125.5, 129.3, 129.7, 156.9, 159.0, 171.7, 193.0 ppm; IR: $\bar{v}=3317(\mathrm{OH}), 1710(\mathrm{C}=\mathrm{O}), 1669$ $(\mathrm{C}=\mathrm{O}) \mathrm{cm}^{-1}$; UV-Vis (methanol, $\left.c=4.65 \cdot 10^{-5} \mathrm{~mol} \mathrm{dm}^{-3}\right): \lambda_{\max }(\varepsilon)$ $=204.5$ (18863.64), $273.0(13873.49) \mathrm{nm}\left(\mathrm{mol}^{-1} \mathrm{dm}^{3} \mathrm{~cm}^{-1}\right) ; \mathrm{MS}$ (EI, $70 \mathrm{eV}$ ): $\mathrm{m} / z=301[\mathrm{M}]^{+}, 284,228,252,115$; HRMS (EI): $\mathrm{m} / z$ calculated for $\mathrm{C}_{17} \mathrm{H}_{19} \mathrm{NO}_{4}[\mathrm{M}]^{+} 301.1314$, found 301.1311.

3-(2-Chlorophenyl)-1-hydroxy-6,6-dimethyl-5,6,7,7a-tetrahydro-1H-indole-2,4-dione (3d). Isolated yield $83 \%$; beige crystals; m.p.: $142-144{ }^{\circ} \mathrm{C}$ (from hexane-acetone). ${ }^{1} \mathrm{H}$ NMR (300 $\mathrm{MHz}, \mathrm{CDCl}_{3}$ ): $\delta=1.14\left(\mathrm{~s}, 3 \mathrm{H}, \mathrm{CH}_{3}\right), 1.17\left(\mathrm{~s}, 3 \mathrm{H}, \mathrm{CH}_{3}\right), 2.24$ (d, $J=16.6 \mathrm{~Hz}, 1 \mathrm{H}, H-5 \alpha), 2.29(\mathrm{~d}, J=16.6 \mathrm{~Hz}, 1 \mathrm{H}, H-5 \beta), 2.54$ (dd, $J=2.8 \mathrm{~Hz}, J=18.4 \mathrm{~Hz}, 1 \mathrm{H}, H-7 \alpha), 2.61$ (dd, $J=1.7 \mathrm{~Hz}$, 
$J=18.4 \mathrm{~Hz}, 1 \mathrm{H}, H-7 \beta), 5.23$ (bs, $1 \mathrm{H}, H-7 \mathrm{a}), 7.16-7.20$ (m, 3H, $3 \mathrm{CH}$ arom), 7.32-7.35 (m, 1H, CH arom) ppm; ${ }^{13} \mathrm{C}$ NMR (75 $\left.\mathrm{MHz}, \mathrm{CDCl}_{3}\right): \delta=28.7,28.9,34.3,36.9,51.19,115.6,127.3$, 129.6, 130.1, 133.4, 134.7, 157,5, 172.4, 193.0 ppm; IR: $\bar{v}=$ $3321(\mathrm{OH}), 1707(\mathrm{C}=\mathrm{O}), 1663(\mathrm{C}=\mathrm{O}) \mathrm{cm}^{-1}$; UV-Vis (methanol, $\left.c=4.85 \cdot 10^{-5} \mathrm{~mol} \mathrm{dm}^{-3}\right): \lambda_{\max }(\varepsilon)=205.0(14718.53), 270.0$ (11028.59) nm $\left(\mathrm{mol}^{-1} \mathrm{dm}^{3} \mathrm{~cm}^{-1}\right)$; MS (EI, $\left.70 \mathrm{eV}\right): \mathrm{m} / z=306$ $[\mathrm{M}+\mathrm{H}]^{+}, 270,252,227,196,155,115$; HRMS (ESI): $\mathrm{m} / z$ calculated for $\mathrm{C}_{16} \mathrm{H}_{17}{ }^{35} \mathrm{ClNO}_{3}[\mathrm{M}+\mathrm{H}]^{+}$306.08970, found 306.08917.

1-Hydroxy-6,6-dimethyl-3-(4-methylphenyl)-5,6,7,7a-tetrahydro-1H-indole-2,4-dione (3e). Isolated yield $57 \%$; orange-brown crystals; m.p.: $169-171{ }^{\circ} \mathrm{C}$ (from hexane-acetone); ${ }^{1} \mathrm{H}$ NMR $\left(300 \mathrm{MHz}, \mathrm{CDCl}_{3}\right): \delta=1.14\left(\mathrm{~s}, 3 \mathrm{H}, \mathrm{CH}_{3}\right), 1.17(\mathrm{~s}$, $3 \mathrm{H}, \mathrm{CH}_{3}$ ), 2.26-2.29 (bs, $5 \mathrm{H}, \mathrm{CH}_{2}-5, \mathrm{CH}_{3}$ arom), 2.55 (dd, $J=$ $2.5 \mathrm{~Hz}, J=18.7 \mathrm{~Hz}, 1 \mathrm{H}, H-7 \alpha$ ), 2.51-2.64 (m, $1 \mathrm{H}, H-7 \beta), 4.85$ $(\mathrm{dd}, J=1.8, J=2.5 \mathrm{~Hz}, 1 \mathrm{H}, H-7 \mathrm{a}), 7.08(\mathrm{~d}, J=7.8 \mathrm{~Hz}, 2 \mathrm{H}$, $2 \mathrm{CH}$ arom), 7.11 (d, $J=7.8 \mathrm{~Hz}, 2 \mathrm{H}, 2 \mathrm{CH}$ arom) ppm, ${ }^{13} \mathrm{C}$ NMR $\left(75 \mathrm{MHz}, \mathrm{CDCl}_{3}\right): \delta=21.2,28.7,28.8,34.4,36.9,45.7,51.3$, 117.1, 127.4, 129.7, 134.4, 137.5, 158.9, 171.7, $193.1 \mathrm{ppm}$; IR: $\bar{v}=3235(\mathrm{OH}), 1706(\mathrm{C}=\mathrm{O}), 1620(\mathrm{C}=\mathrm{O}) \mathrm{cm}^{-1}$; UV-Vis (methanol, $\left.c=4.49 \cdot 10^{-5} \mathrm{~mol} \mathrm{dm}^{-3}\right): \lambda_{\max }(\varepsilon)=206.0(15014.40), 270.0$ (12051.62) nm $\left(\mathrm{mol}^{-1} \mathrm{dm}^{3} \mathrm{~cm}^{-1}\right)$; MS (EI, $\left.70 \mathrm{eV}\right): \mathrm{m} / z=285$ $[\mathrm{M}]^{+}, 268,255,201,115$; HRMS (EI): $m / z$ calculated for $\mathrm{C}_{17} \mathrm{H}-$ ${ }_{19} \mathrm{NO}_{3}[\mathrm{M}]^{+} 285.1365$, found 285.1368 .

3-(4-Bromophenyl)-1-hydroxy-6,6-dimethyl-5,6,7,7a-tetrahydro-1H-indole-2,4-dione (3f).

Isolated yield $64 \%$; yellowish-orange crystals; m.p.: $96-98^{\circ} \mathrm{C}$ (from hexane-acetone). ${ }^{1} \mathrm{H}$ NMR $\left(300 \mathrm{MHz}, \mathrm{CDCl}_{3}\right): \delta=1.09$ (s, $\left.3 \mathrm{H}, \mathrm{CH}_{3}\right), 1.11\left(\mathrm{~s}, 3 \mathrm{H}, \mathrm{CH}_{3}\right), 2.18(\mathrm{~d}, J=16.6 \mathrm{~Hz}, 1 \mathrm{H}, H-5 \alpha)$, 2.24 (d, $J=16.6 \mathrm{~Hz}, 1 \mathrm{H}, H-5 \beta), 2.51$ (dd, $J=2.8 \mathrm{~Hz}, J=18.4$ $\mathrm{Hz}, 1 \mathrm{H}, H-7 \alpha), 2.54$ (dd, $J=1.5 \mathrm{~Hz}, J=18.4 \mathrm{~Hz}, 1 \mathrm{H}, H-7 \beta)$, $4.82(\mathrm{dd}, J=2.1, J=2.8 \mathrm{~Hz}, 1 \mathrm{H}, H-7 \mathrm{a}), 7.09$ (d, $J=8.5 \mathrm{~Hz}$, $2 \mathrm{H}, 2 \mathrm{CH}$ arom), 7.43 (d, $J=8.5 \mathrm{~Hz}, 2 \mathrm{H}, 2 \mathrm{CH}$ arom) ppm, ${ }^{13} \mathrm{C}$ $\operatorname{NMR}\left(75 \mathrm{MHz}, \mathrm{CDCl}_{3}\right): \delta=28.5,28.6,34.4,36.9,44.9,51.1$, 116.6, 121.4, 129.4, 131.8, 134.5, 157.8, 172.2, 193.0 ppm; IR: $\bar{v}=3213(\mathrm{OH}), 1701(\mathrm{C}=\mathrm{O}), 1645(\mathrm{C}=\mathrm{O}) \mathrm{cm}^{-1}$; UV-Vis (methanol, $\left.c=3.78 \cdot 10^{-5} \mathrm{~mol} \mathrm{dm}^{-3}\right): \lambda_{\max }(\varepsilon)=204.5(14066.97)$, $269.0(10100.72) \mathrm{nm}\left(\mathrm{mol}^{-1} \mathrm{dm}^{3} \mathrm{~cm}^{-1}\right)$; MS (EI, $\left.70 \mathrm{eV}\right): \mathrm{m} / z=$ $349[\mathrm{M}]^{+}, 334,270,253,227,155,115,83$; HRMS (EI): $\mathrm{m} / \mathrm{z}$ calculated for $\mathrm{C}_{16} \mathrm{H}_{16}{ }^{79} \mathrm{BrNO}_{3}[\mathrm{M}]^{+} 349.0314$, found 349.0305 .

\section{Hydrogenation-dehydrogenation reactions of $\mathbf{3 a}$ to give products 4 and 5 .}

\footnotetext{
6,6-dimethyl-3-phenyl-1,2,5,6,7,7a-hexahydro-4H-indole-4one (4). To a suspension of Raney Nickel (400 mg) previously activated and prehydrogenated, in dry ethanol $(15 \mathrm{~mL})$, the compound 3a was added $(2.2 \mathrm{mmol})$ in dry ethanol $(10 \mathrm{~mL})$. The mixture was hydrogenated at $5 \mathrm{~atm}$. until no more hydrogen is consumed. The reaction mixture was filtered on celite, the solution evaporated and the residue purified by silica gel
}

column chromatography (hexane-ethyl acetate 90:10 as eluent), to give the product $4(175 \mathrm{mg}), 33 \%$ yield; yellow crystals; m.p.: $232-234{ }^{\circ} \mathrm{C}$ (from hexane-ethyl acetate). ${ }^{1} \mathrm{H}$ NMR (300 $\mathrm{MHz}, \mathrm{CDCl}_{3}$ ): $\delta=0.92\left(\mathrm{~s}, 3 \mathrm{H}, \mathrm{CH}_{3}\right), 1.04\left(\mathrm{~s}, 3 \mathrm{H}, \mathrm{CH}_{3}\right), 2.00$ (s, $\left.2 \mathrm{H}, \mathrm{CH}_{2}-7\right), 2.3$ (s, $\left.2 \mathrm{H}, \mathrm{CH}_{2}-5\right), 3.28$ (dd, $J=4.8, \mathrm{~J}=10.5 \mathrm{~Hz}$, $1 \mathrm{H}, H-2 \alpha), 3.95(\mathrm{t}, J=11.1 \mathrm{~Hz}, \mathrm{H}-2 \beta), 4.15$ (dd, $J=4.8, J=11.1$ $\mathrm{Hz}, 1 \mathrm{H}, \mathrm{H}-3), 7.19-7.32$ (m, 5H, 5CH arom) ppm, ${ }^{13} \mathrm{C}$ NMR $\left(75 \mathrm{MHz}, \mathrm{CDCl}_{3}\right): \delta=28.0,28.8,33.6,36.8,43.4,50.5,55.3$, 105.2, 125.8, 126.8, 127.6, 139.3, 146.1, 186.4 ppm; IR (KBr): $\bar{v}=3396(\mathrm{NH}), 1587(\mathrm{C}=\mathrm{O}), 11481(\mathrm{C}=\mathrm{C}) \mathrm{cm}^{-1}$; MS (EI, 70 $\mathrm{eV}): m / z=241[\mathrm{M}]^{+}, 240,184,164,157,128,83$. HRMS (EI): $\mathrm{m} / \mathrm{z}$ calculated for $\mathrm{C}_{16} \mathrm{H}_{19} \mathrm{NO}[\mathrm{M}]^{+} 241.1466$, found 241.1445.

6,6-dimethyl-3-phenyl-1,5,6,7-tetrahydro-4H-indole-4-one (5). The compound $4(0.5 \mathrm{mmol})$ in toluene anhydrous $(10 \mathrm{~mL})$ was refluxed in the presence of $10 \% \mathrm{Pd} / \mathrm{C}(10 \mathrm{mg})$ for $3 \mathrm{~h}$. The reaction mixture was filtered on celite, the solution evaporated and the residue purified by silica gel column chromatography (hexane-ethyl acetate 60:40 as eluent), to give compound 5 (52 $\mathrm{mg}$ ), $43 \%$ yield;white crystals; m.p.: $245-247{ }^{\circ} \mathrm{C}$ (from hexane-ethyl acetate). ${ }^{1} \mathrm{H}$ NMR ( $300 \mathrm{MHz}, \mathrm{CDCl}_{3}$ ): $\delta=1.14$ (s, $\left.6 \mathrm{H}, 2 \mathrm{xCH}_{3}\right), 2.42\left(\mathrm{~s}, 2 \mathrm{H}, \mathrm{CH}_{2}-5\right), 2.2 .69\left(\mathrm{~s}, 2 \mathrm{H}, \mathrm{CH}_{2}-7\right), 6.71$ (s, $1 \mathrm{H}, H-2), 7.24\left(\mathrm{t}, J=7.5 \mathrm{~Hz}, 1 \mathrm{H}, H-4^{\prime}\right), 7.34(\mathrm{t}, J=7.5 \mathrm{~Hz}, 2 \mathrm{H}$, $\left.H-3^{\prime}, H-5^{\prime}\right), 7.64$ (d, $\left.J=7.5 \mathrm{~Hz}, 2 \mathrm{H}, H-2^{\prime}, H-6^{\prime}\right), 7.35-7.63$ (m, $5 \mathrm{H}, 5 \mathrm{CH}$ arom.) ppm, ${ }^{13} \mathrm{C} \mathrm{NMR}\left(75 \mathrm{MHz}, \mathrm{CDCl}_{3}\right): \delta=28.6$, 35.6, 37.4, 53.3, 115.9, 117.4, 125.0, 126.7, 128.0 128.7, 134.3, 144.0, 193.8 ppm; IR: $\bar{v}=3259(\mathrm{NH}), 1633(\mathrm{C}=\mathrm{O}), \mathrm{cm}^{-1}$; MS (EI, $70 \mathrm{eV}): m / z=239[\mathrm{M}]^{+}, 183,154,125,97,84$. HRMS (EI): $\mathrm{m} / \mathrm{z}$ calculated for $\mathrm{C}_{16} \mathrm{H}_{17} \mathrm{NO}[\mathrm{M}]^{+}$239.1310, found 239.1319.

\section{Cytotoxicity evaluation}

Cancer lines were obtained from the National Cancer Institute of the United States. Cytotoxicity data were determined using the protein-bound-sulforhodamine (SRB) assay in microculture; the assay measures cell proliferation as described by Monks method [21]. Cell lines were cultivated in RPMI-1640 medium with $10 \%(\mathrm{v} / \mathrm{v})$ fetal bovine serum, $2 \mu \mathrm{M}$-glutamine, $100 \mathrm{IU} / \mathrm{cm}^{3}$ penicillin $\mathrm{G}, 100 \mathrm{mg} / \mathrm{cm}^{3}$ streptomycin sulfate, and $0.25 \mu \mathrm{g} / \mathrm{cm}^{3}$ of amphotericin B (Gibco Grand Island, NY). The incubation was at $37{ }^{\circ} \mathrm{C}$ in a $5 \%, \mathrm{CO}_{2}$ atmosphere and $100 \%$ relative humidity. After replication, cells were detached with a $0.05 \%(\mathrm{w} / \mathrm{v})$ trypsin-EDTA solution, counted in a hemocytometer, and diluted with complete medium to $5 \times 10^{3}$ cells $/ \mathrm{cm}^{3}(\mathrm{~K}-$ 562, MCF-7), $7.5 \times 10^{3}$ cells $/ \mathrm{cm}^{3}$ (U-251, PC-3, and SKLU-1), or $10 \times 10^{3}$ cells $/ \mathrm{cm}^{3}$ (HTC-15).

Microtiter plate wells were filled with $100 \mathrm{~mm}^{3}$ aliquots of cell suspension and incubated. After $24 \mathrm{~h}$ cells were treated with logarithmically diluted concentrations of sample compounds. Test samples were dissolved in DMSO to provide stock solutions $(40 \mu \mathrm{M})$ and were then diluted to yield solutions of 100 , $31,10,3.1$ and $1 \mu \mathrm{M}$, for use in treatment of cell suspensions. After $48 \mathrm{~h}$, cultures were fixed in situ by addition of $50 \mathrm{~mm}^{3}$ $50 \%(\mathrm{w} / \mathrm{v})$ trichloroacetic acid and incubated for $60 \mathrm{~min}$ at 4 ${ }^{\circ} \mathrm{C}$. Cells were harvested by centrifugation, washed three times, 
and dried. Cell pellets were suspended in $100 \mathrm{~mm}^{3} 0.4 \%(\mathrm{w} / \mathrm{v})$ $\mathrm{SRB}$ solution in $1 \%(\mathrm{v} / \mathrm{v})$ acetic acid for $30 \mathrm{~min}$. Unbound SRB was removed by washing with $1 \%(\mathrm{v} / \mathrm{v})$ acetic acid and protein-linked dye was extracted with $10 \mu \mathrm{M}$ tris(hydroxymethyl) methaneamine solution, and quantitated by spectrometry at 515 $\mathrm{nm}$. The $\mathrm{IC}_{50}$ values were calculated according to Monks [21].

\section{Acknowledgements}

We are very grateful to CONACYT-México for Ph.D. scholarship (182167) and to the Programa de Posgrado en Ciencias Químicas-UNAM. We also thank R. Patiño, M. A. Peña, L. Velasco and J. Pérez for technical assistance, and to M. T. RamírezApan for the cytotoxicity assays.

\section{References}

1. Del Prete, G. Q.; Shoemaker, R.; Oswald, K.; Lara, A.; Trubey, C. M.; Fast, R.; Schneider, D. K.; Kiser, R.; Coalter, V.; Wiles, A.; Wiles, R.; Freemire, B.; Keele, B. F.; Estes, J. D.; Quiñones, O. A.; Smedley, J.; Macallister, R.; Sanchez, R. I.; Wai, J. S.; Tan, C. M.; Alvord, W. G.; Hazuda, D. J.; Piatak, M. Jr.; Lifson, J. D. Antimicrob. Agents Chemother. 2014, 58, 6790.

2. Yadav, R.; Murthy, R. V.; Kikkeri, R. Chembiochem. 2015, 16, 1448.

3. Domingo, J. L. Reprod. Toxicol. 1998, 12, 499.

4. Cabantchik, Z. I. Parasitol. Today. 1995,11, 74.

5. Igeta, K.; Tobbeto, K.; Saiki, I.; Odake, S.; Fujisawa, T.; Matsuo, T.; Oku, T. PCT Int. App. WO 003703, 2000.

6. AndaloussI, M.; Lindh, M.; Björkelid, C; Suresh, S.; Wieckowska, A.; Iyer, H.; Karlén, A.; Larhed, M. Bioorg. Med. Chem. Lett. 2011, 21, 5403.

7. Finnin, M. S; Donigian, J. R.; Cohen, A.; Richon, V. M.; Rifkind, R. A.; Marks, P. A.; Breslow, R.; Pavletich, N. P. Nature 1999, $401,188$.

8. Roberts, K. P.; Iyer, R. A.; Prasad, G.; Liu, L. T.; Lind, R. E.; Hanna, P. E. Prostate. 1998, 34, 92.
9. Joshi, B.; Li, L.; Taffe, B. G.; Zhu, Z.; Wahl, S.; Tian, H.; Ben-Josef, E.; Taylor, J. D.; Porter, A. T.; Tang, D. G. Cancer Res. 1999, 59, 4343.

10. Butler, L. M.; Agus, D. B.; Scher, H. I.; Higgins, B.; Rose, A.; Cordon-Cardo, C.; Thaler, H. T.; Rifkind, R. A.; Marks, P. A.; Richon, V. M. Cancer Res. 2000, 60, 5165.

11. Cheng, P.; Chen, J. J.; Huang, N.; Wang, R. R.; Zheng, Y. T.; Liang, Y. Z. Molecules. 2009, 14, 3176.

12. Pathe, G. K.; Ahmed, N. Tetrahedron Lett. 2015, 56, 6202.

13. Kumar, M. S.; Rajanna, K. C.; Reddy, K. R.; Venkateswarlu, M.; Venkanna, P. Synth. Commun. 2013, 43, 2672.

14. Özdemir, H. S.; Şahin, E.; Çakici, M.; Kiliç, H. Tetrahedron. 2015, 71, 2882.

15. Larson, H.O.; Ooi, T. C.; Siu, A. K. Q.; Hollenbeak, K. H.; Cue, F. L. Tetrahedron. 1969, 25, 4005.

16. Tehrani, M. H. H; Farnia, M.; Nazer, M. S. Iran. J. Pharm. Res. 2003, 2,1 .

17. Basel, Y.; Hassner, A. Synthesis. 1997, 309.

18. Thomas-Mendivil, E.; Suárez, F. J.; Diez, J.; Cadierno, V. Chem. Commun. 2014, 50, 9661.

19. Ishikawa, T.; Miyahara, T.; Asakura, M.; Higuchi, S.; Miyauchi, Y.; Saito, S. Org. Lett. 2005, 7, 1211.

20. The synthesis of compound $\mathbf{5}$ was carried out starting from styrene which reacts with $\mathrm{Br}_{2}$ in $\mathrm{CCl}_{4}$ at room temperature to give (1,2-dibromoethyl)benzene. The dibromo derivative reacts first with $\mathrm{NaN}_{3}$ at room temperature and then with $\mathrm{NaOH}$ solution at $10^{\circ} \mathrm{C}$, both reactions in DMSO to give (1-azidoethenyl)benzene. Hortmann, A. G.; Robertson, D. A.; Gillard, B. K. J. Org. Chem. 1972, 37,322 . Afterwards, the pyrolysis of the former product at $150{ }^{\circ} \mathrm{C}$ in $\mathrm{CH}_{2} \mathrm{Cl}_{2}$ in a high pressure stainless steel reactor with hermetic seal, gives the corresponding $2 H$-azirine. Timén, Å. S.; Risberg, E.; Somfai, P. Tetrahedron Lett. 2003, 44, 5339. Treatment of the azirine with dimedone in acetone and the $\mathrm{Ni}(\mathrm{acac})_{2}$ as the catalyst at $35-40{ }^{\circ} \mathrm{C}$ for $15 \mathrm{~min}$, then $3 \mathrm{~h}$ at room temperature leads to the desired compound 5. Dos Santos Fihlo, P. F.; Schuchardt, U. Angew. Chem. Int. Ed. Engl. 1977, 16, 647.

21. Skehan, P.; Storeng, R.; Scudiero, D.; Monks, A.; McMahon, J.; Vistica, D.; Warren, J. T.; Bokesch, H.; Kenney, S.; Boyd, M. R. J. Natl. Cancer Inst. 1990, 82, 1107. 